\title{
Peroxidase Activity in the Sulfate-Reducing Bacterium Desulfotomaculum acetoxidans DSM 771
}

\author{
LUCYNA PAWŁOWSKA-ĆWIĘK* \\ Institute of Biology, Pedagogical University of Cracow, Kraków, Poland
}

Received 14 December 2009, revised 22 July 2010, accepted 21 September 2010

Abstract

\begin{abstract}
Earlier research demonstrated the secretion of benzoate, which must be oxygenated to its 4-hydroxy derivative in order to be included in further sulfate uptake processes. The present study on Desulfotomaculum acetoxidans DSM 771 was designed to determine the activity and catalytic specificity of the enzyme (most probably peroxidase) catalyzing the hydroxylation of secreted benzoate. Peroxidase activity measured with ABTS (2,2'-azino-bis (3-ethylbenzathiazoline-6-sulfonic acid) during cultivation indicated the greatest activity on the third and thirteen days (3.4 and 2.3 nkat per ml sample respectively). The highest (0.7979) correlation coefficient was calculated between peroxidase activity and hydrogen peroxide levels. The cell walls from 3- and 13-day cultures were subjected to an isolation procedure, PIPES (piperazine-N,N'-bis (2-ethane-sulfonic acid) extract followed by preparative electrophoresis. The extracts of a $\sim 30 \mathrm{kDa}$ band on the gel were analyzed by Western blotting and the membrane was stained with TMB $\left(3,3^{\prime}, 5,5^{\prime}\right.$ 'tetramethylbenzidine-specific for the presence of peroxidase). This same protein was incubated for $6 \mathrm{~h}$ with benzoate, $\mathrm{H}_{2} \mathrm{O}_{2}, \mathrm{Na}_{2} \mathrm{SO}_{4}$. The product formed a complex with $\mathrm{Fe}^{3+}$, whose maximum absorption spectra $(501.7 \mathrm{~nm})$ corresponded with a ferric complex of synthetic 4-hydroxy-3-sulfo-benzoate. The $\mathrm{H}_{2} \mathrm{~S}$ level during the cultivation was higher in culture grown with $15.5 \mathrm{mM}$ 4-hydroxy-3-sulfo-benzoate than in culture with lactate supplemented with $15.5 \mathrm{mM}$ sulfate. The role of peroxidase in oxygen utilization and sulfate uptake is discussed.
\end{abstract}

K e y words: Desulfotomaculum acetoxidans, specificity and activity of peroxidase

\section{Introduction}

Sulfate-reducing bacteria (SRB) are capable not only of sulfur assimilation but also of the dissimilative reduction of sulfate or sulfur. Consequently, the mode of sulfate fixation and transport processes is very important for their metabolism. On the other hand, it is very interesting and essential for environmental biotechnology, that sulfate-reducing bacteria are capable of the biodegradation and catabolic utilization of monoaryls under anaerobic conditions (Schink et al., 1992; Rabus and Widdel, 1995; Noh et al., 2003). Kuever et al. (1993) found very rapid growth of an isolated SRB strain, especially on benzoate and 4-hydroxy-benzoate. However, it is still not clear in what way those obligatory anaerobes can oxidize benzoate, which is required for such biodegradation (Schink et al., 1992).

Admittedly, among the proteins that were more abundant under oxygen exposure of Desulfovibrio vulgaris Hildenborough, thiol-peroxidase was identified but its function was not established (Fournier et al., 2006). Moreover, the authors suggested the cytoplasmic location of this protein.
The finding of benzoate secretion by Desulfotomaculum acetoxidans should change opinion regarding the metabolic role of this aryl in cell walls (PawłowskaĆwięk and Pado, 2005). The authors proposed the following sequence of sulfate uptake processes occurring, especially during lag phase: 1 . Secretion of benzoate; 2. Oxidation of the ring in position $4 ; 3$. Sulfonation of 4-hydroxybenzoate.

Since the second step requires enzymatic participation, because the product of the spontaneous benzoate oxydation is 3-hydroxy-benzoate, we pursued further research on this putative cell wall enzyme, which is described herein.

\section{Experimental}

\section{Materials and Methods}

Growth of organism. Desulfotomaculum acetoxidans strain DSM 771 was cultivated at room temperature (about $20^{\circ} \mathrm{C}$ ) in a medium with $42 \mathrm{mM}$ sodium lactate as a catabolic substrate (Pawłowska-Ćwięk and Pado, 2007). Other medium components were as

\footnotetext{
* Corresponding author: L. Pawłowska-Ćwięk, Institute of Biology, Pedagogical University of Cracow, ul. Podbrzezie 3, 31-054 Kraków, Poland; email: lpc@ap.krakow.pl
} 
previously (Pado and Pawłowska-Ćwięk, 2004; Pawłowska-Ćwięk and Pado, 2005). After autoclaving and inoculation, the media were immediately covered with a liquid paraffin layer (about $5 \mathrm{~mm}$ thick). Moreover, the independent stationary cultures of this strain were carried out under anoxic conditions in $15.5 \mathrm{mM}$ synthetic 4-hydroxy-3-sulfo-benzoate or $31.0 \mathrm{mM}$ lactate plus $15.5 \mathrm{mM}$ sulfate-containing media. The synthesis of 4-hydroxy-3-sulfo-benzoate was obtained by sulfonation of 4-hydroxy-benzoate and purified by HPLC and a detailed chemical analysis of this compound will be carried out separately.

Measurements during cultivation. Peroxidase activity was determined spectrophotometrically by using 2,5 mM ABTS (2,2'-azino-bis (3-ethylbenzathiazoline-6-sulfonic acid) (Szutowicz et al., 1984) in $10 \mathrm{~min}$ aerated samples. The samples were aerated, because of content of reducers, e.g. reduced glutatione (GSH) and sulfide (Bartosz and Bartosz, 1999) which inactivated the colored positive radical of ABTS. Monitoring of the change in absorbance at $419 \mathrm{~nm}$ was performed from $15 \mathrm{~min}$ to $4 \mathrm{~h}$. Activity (in nkatales) was calculated assuming $\mathrm{E}_{\mathrm{ABTS}} \approx 24600$ (Luterek et al., 1997) and recalculated for mg proteins. Because most peroxidases require hydrogen peroxide and frequently oxygen for their activity, $\mathrm{H}_{2} \mathrm{O}_{2}$ and $\mathrm{O}_{2}$ levels were measured in these cultures as well. The hydrogen peroxide level was determined according to Pick (1986). The oxygen concentration was measured by potentiometric method by using CTN-980R oxygen detector (ELSENT Poland) coupled to a CX-315 microcomputer $\mathrm{pH} /$ oxygenmeter (ELMETRON Poland); the assay method was described previously (PawłowskaĆwięk and Pado, 2007). Moreover, in additional cultures with 4-hydroxy-3-sulfo-benzoate or lactate plus sulfate, the concentration of hydrogen sulfide was measured using the methylene blue method (Fago and Popowsky, 1949). The results of triplicate assays are presented as arithmetic mean for oxygen and hydrogen sulfide. The correlation coefficients were calculated using Excel program commonly.

Preparation of cell wall extract. After 3 days of cultivation, 11 culture was aerated $\left(\mathrm{O}_{2}\right.$ total amount was approximately 450 mmoles) for $12 \mathrm{~h}$ and then centrifuged at $2,500 \times \mathrm{g}$ for $25 \mathrm{~min}$. The cell biomass pallet was retained while the supernatant was evaporated to about $50 \mathrm{ml}$ at $8^{\circ} \mathrm{C}$. The shaken suspension was centrifuged at $10,000 \times \mathrm{g}$ for $15 \mathrm{~min}$ and a lysozyme solution $\left(10^{5} \mathrm{U} / 1 \mathrm{ml} 10 \mathrm{mM}\right.$ Tris buffer, $\mathrm{pH}$ 6.9) was added to the pellet, to degrade peptidoglycan. The suspension was shaken and incubated for $48 \mathrm{~h}$ and re-centrifuged. The pellets were than extracted with 2 mM PIPES (piperazine-N,N'-bis (2-ethane-sulfonic acid) buffer ( $\mathrm{pH} 5.5)$ for $24 \mathrm{~h}$. This operation was repeated three times and the extracts were pooled. An identical procedure was carried out for a 13-day culture. On the other hand, the pellet from the 10-day culture (which was not aerated) after the above procedure was extracted with phosphate buffer ( $\mathrm{pH}$ 7.6) for the presence of catalase.

Purification of peroxidase. The crude PIPES extracts were analyzed by sodium dodecyl sulfate-polyacrylamide gel electrophoresis (SDS-PAGE) and stained with Coomassie blue G-250. Since it was assumed that this peroxidase too (like almost all of those known so far) is a hemoprotein, in order to locate it on the gel, staining with 3,3'-diaminobenzidine (McDonnel and Staehelin, 1981) and 3,3'-dimetoxybenzidine (Francis and Becker, 1984) was employed. The final PIPES extract was purification by non-denaturing preparative polyacrylamide gel (15\%) electrophoresis (PAGE). The $\sim 30 \mathrm{kDa}$ band containing hemoprotein, eluting at $10 \mathrm{mM}$ Tris- $\mathrm{HCl}(\mathrm{pH}$ 6.1), was collected. The peroxidase activity in final extract was determined and calculated as above.

Activity staining. The final Tris- $\mathrm{HCl}$ extracts from 3- and 13-days cultures containing $75 \mathrm{mg}$ proteins after Western blotting onto PVDF - Immobilon ${ }^{\mathrm{TM}}-\mathrm{P}{ }^{\mathrm{SQ}}$ membrane were stained with TMB (3,3',5,5'-tetramethylbenzidine) in accordance with SIGMA instruction.

Testing catalytic specificity of peroxidase. The final Tris- $\mathrm{HCl}$ extract $(2 \mathrm{ml})$ of 3-day culture was incubated with equal volumes of $5 \mathrm{mM}$ benzoate, $400 \mathrm{mM}$ hydrogen peroxide and $80 \mathrm{mM}$ sodium sulfate for $6 \mathrm{~h}$ at room temperature. The product of this incubation formed a colored complex with $207 \mathrm{mM}$ $\mathrm{Fe}\left(\mathrm{NH}_{4}\right)\left(\mathrm{SO}_{4}\right)_{2}$ in $1 \mathrm{M} \mathrm{HCl}$; this complex was analyzed spectrophotometrically.

Test of catalase presence. The collected phosphate extract from 10-day culture was analyzed by nondenaturing electrophoresis and gel staining according to Woodbury et al. (1971).

Spectrophotometric analysis. The enzymatic assays and spectral analyses were performed using a CECIL 8020 spectrophotometer (bandwidth $2 \mathrm{~nm}$ and path length $10 \mathrm{~mm}$ ).

The chemicals and reagents (except for 4-hydroxy3-sulfo-benzoate) were obtained from Merck, Fluka or Sigma Chemical Companies.

\section{Results}

The obtained results showed highest peroxidase activity on days 3 and 13 (3.423 and 2.338 nkatales per $\mathrm{ml}$ sample, respectively) (Fig. 1). The calculated correlation coefficient between peroxidase activity and hydrogen peroxide or oxygen level was -0.0516 and -0.10579 , respectively, for the entire cultivation period (Table I). However, if the assumption is made that hydrogen peroxide induces peroxidase then in the calculation hydrogen peroxide level should precede 


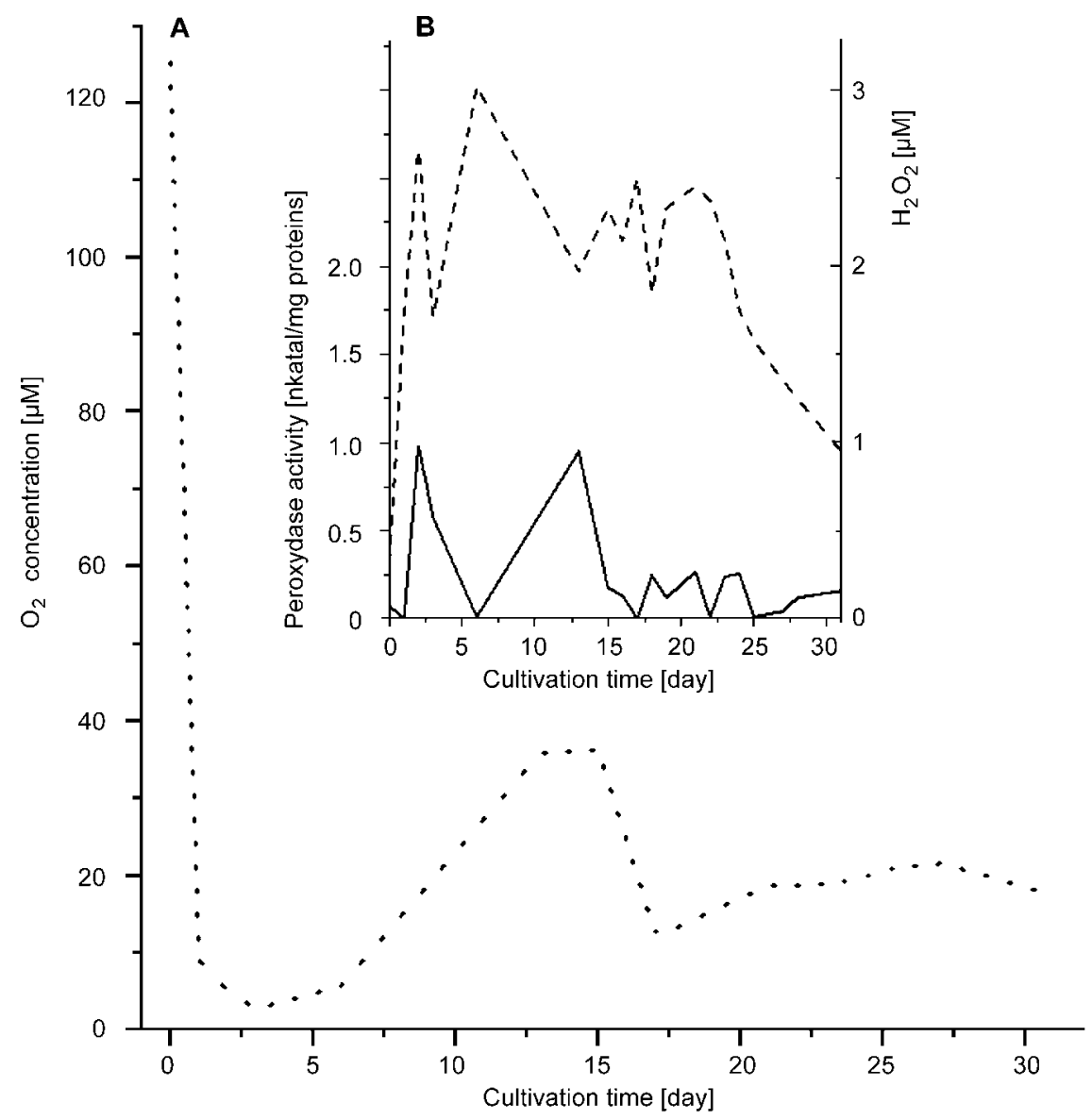

Fig. 1. Oxygen concentration ( $\mathbf{A}$ - dotted line), peroxidase activity $(\mathbf{B}$ - solid line) and hydrogen peroxide level (B - dashed line) during cultivation of Desulfotomaculum acetoxidans in lactate plus sulfate containing medium.

peroxidase activity by one day. Thus the following correlation coefficients were calculated: 0.55406 - if hydrogen peroxide level from 2 to 30 day and peroxidase activity from 3 to 31 day and -0.236 for peroxidase activity $v s$ oxygen level. The highest coefficient 0.79794 was obtained when the values of peroxidase activity from days 3-17 were assigned to the values for hydrogen peroxide concentration from days 2-16. While, negative correlation coefficients peroxidase activity $v s$ oxygen level $(-0.253$ or -0.285$)$ were obtained when peroxidase activity values from 2 to 31 day were assigned of oxygen level values from start to 29 day or peroxidase activity from days $2-19$ and oxygen level from days start to 17 , respectively.

Table I

Correlation coefficients.

\begin{tabular}{|l|c|c|c|}
\hline \multicolumn{1}{|c|}{$\begin{array}{c}\text { Cultivation period } \\
\mathrm{t}_{\text {start day }}-\mathrm{t}_{\text {last day }}\end{array}$} & $\begin{array}{c}\text { Peroxidase activity } \\
\text { (P.a.) } v s \mathrm{H}_{2} \mathrm{O}_{2} \text { level }\end{array}$ & $\begin{array}{c}\text { Peroxidase activity } \\
\text { (P.a.) } v s \mathrm{O}_{2} \text { level }\end{array}$ & $\begin{array}{c}\mathrm{H}_{2} \mathrm{O}_{2} \text { level } \\
\text { vs } \mathrm{O}_{2} \text { level }\end{array}$ \\
\hline Both factors $\mathrm{t}_{0}-\mathrm{t}_{31}$ & -0.05162 & -0.10579 & -0.16188 \\
\hline Both factors $\mathrm{t}_{2}-\mathrm{t}_{31}$ & -0.12478 & & \\
\hline P.a. $\mathrm{t}_{3}-\mathrm{t}_{31}$ and $\mathrm{H}_{2} \mathrm{O}_{2} \mathrm{t}_{2}-\mathrm{t}_{30}$ & 0.55406 & & \\
\hline P.a. $\mathrm{t}_{3}-\mathrm{t}_{24}$ and $\mathrm{H}_{2} \mathrm{O}_{2} \mathrm{t}_{2}-\mathrm{t}_{23}$ & 0.64652 & & \\
\hline P.a. $\mathrm{t}_{3}-\mathrm{t}_{17}$ and $\mathrm{H}_{2} \mathrm{O}_{2} \mathrm{t}_{2}-\mathrm{t}_{16}$ & 0.79794 & & \\
\hline P.a. $\mathrm{t}_{1}-\mathrm{t}_{31}$ and $\mathrm{O}_{2} \mathrm{t}_{0}-\mathrm{t}_{30}$ & & -0.236 & \\
\hline P.a. $\mathrm{t}_{2}-\mathrm{t}_{31}$ and $\mathrm{O}_{2} \mathrm{t}_{0}-\mathrm{t}_{29}$ & & -0.25282 & \\
\hline P.a. $\mathrm{t}_{2}-\mathrm{t}_{24}$ and $\mathrm{O}_{2} \mathrm{t}_{0}-\mathrm{t}_{22}$ & & -0.28475 & -0.18063 \\
\hline Both factors $\mathrm{t}_{1}-\mathrm{t}_{31}$ & & & -0.18587 \\
\hline Hot $\mathrm{O}_{2} \mathrm{t}_{1}-\mathrm{t}_{31}$ and $\mathrm{O}_{2} \mathrm{t}_{0}-\mathrm{t}_{30}$ & & & -0.7937 \\
\hline Both factors $\mathrm{t}_{1}-\mathrm{t}_{23}$ & & & \\
\hline
\end{tabular}




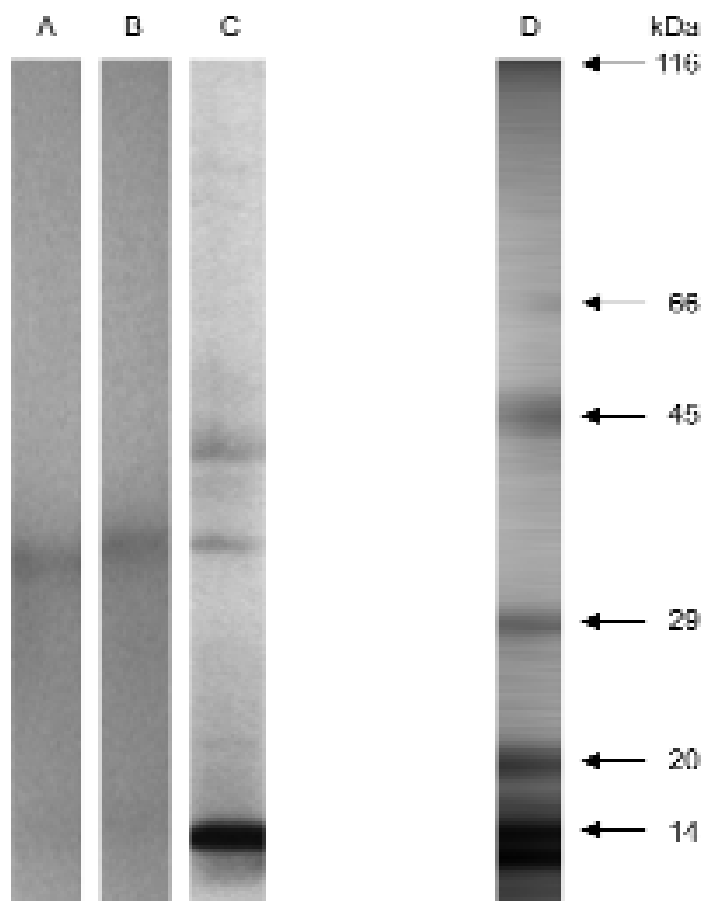

Fig. 2. PAGE-SDS gels (15\%) stained: A - 3,3'-diaminobenzidine; B - 3,3'-dimetoxybenzidine; C - Coomassie blue G-250; $\mathrm{D}$ - molecular weight markers.

Based on the assumption that peroxidase is a hemoprotein, it was located on the gel by using 3,3'-dimetoxybenzidine. The molecular mass of this hemoprotein $(\sim 30 \mathrm{kDa})$ was determined by SDS-PAGE and compared with standard proteins (Fig. 2). After Western blotting this purified hemoprotein was transferred onto a membrane which was stained with TMB. The obtained result showed a blue spot characteristic for peroxidase in both the day 3 and day 13 cultures (Fig. 3). The peroxidase activity was 51.3 ncatales per ml sample.

The product of the incubation (purified peroxidase with benzoate, hydrogen peroxide and sodium sul-

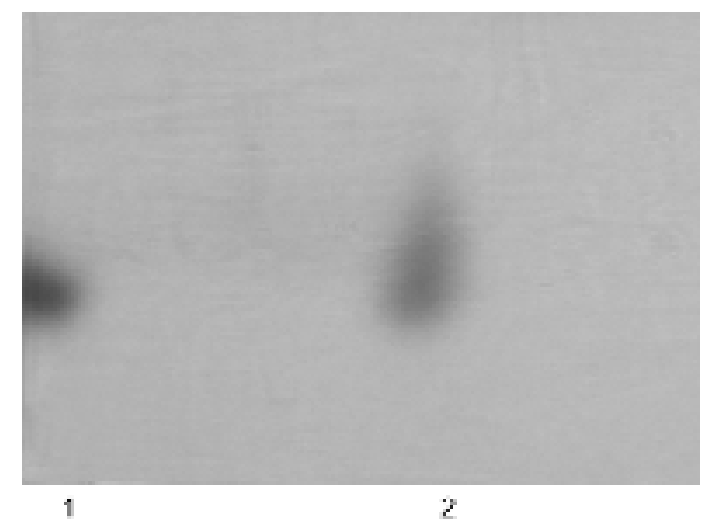

Fig. 3. Purified peroxydase from aerated 3-day (1) and 13-day (2) cultures of Desulfotomaculum acetoxidans after Western blotting onto PVDF - Immobilon ${ }^{\mathrm{TM}}-\mathrm{P}^{\mathrm{SQ}}$ membrane stained 3,3',5,5'-tetramethylbenzidine (TMB) in accordance with SIGMA instruction.

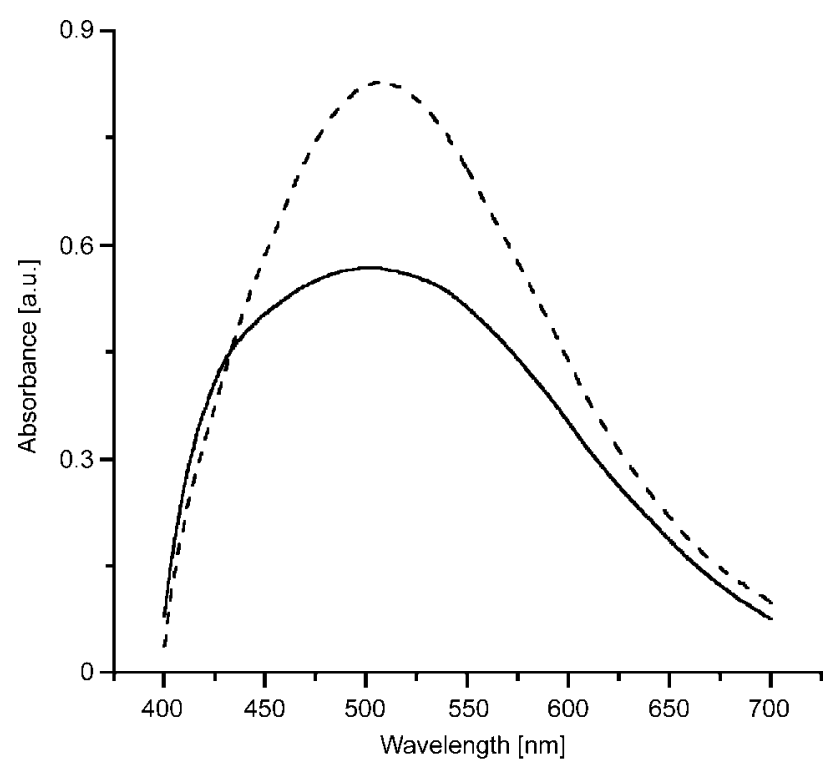

Fig. 4. Absorption spectra of ferrous complexes: TRIS extract from preparative gel (band $\sim 30 \mathrm{kDa}$ - peroxidase) after incubation with benzoate, hydrogen peroxide and sodium sulfate (solid line) $\left(1_{\max }=501.7 \mathrm{~nm}\right)$ from 3 -day culture

of $D$. acetoxidans and synthetic 4-hydrohy3-sulfo-benzoate (dotted line) $(\max =503,8 \mathrm{~nm})$.

fate) formed a colored complex with iron present in $\mathrm{Fe}\left(\mathrm{NH}_{4}\right)\left(\mathrm{SO}_{4}\right)_{2}$ solution The maximum absorption at $501.7 \mathrm{~nm}$ of this complex was almost identical with the ferrous complex $(503.8 \mathrm{~nm})$ of synthetic 4-hydroxy-3-sulfo-benzoate (Fig. 4).

Monitoring measurements showed an increase of oxygen level in the second week of the cultivation (Fig. 1).

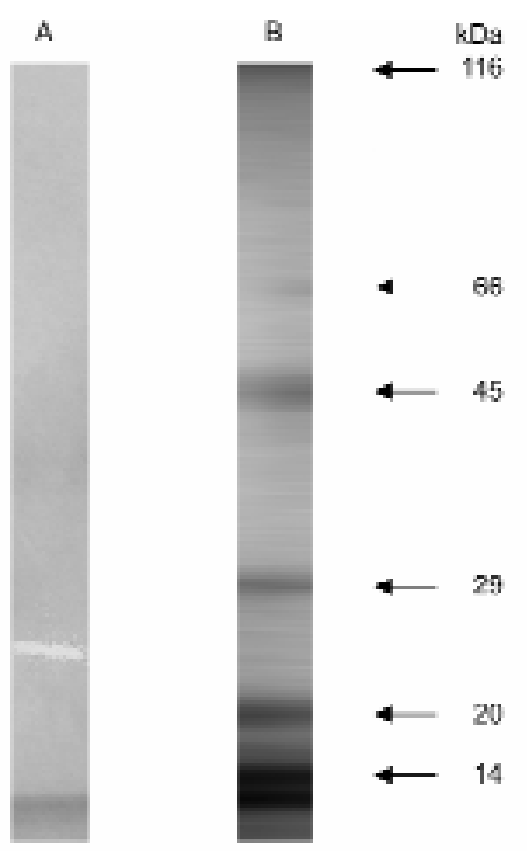

Fig. 5. Gel after non-denaturing electrophoresis and staining the mixture ferric chloride and potassium ferrocyanide (A); $\mathrm{B}$ - molecular weight markers. 


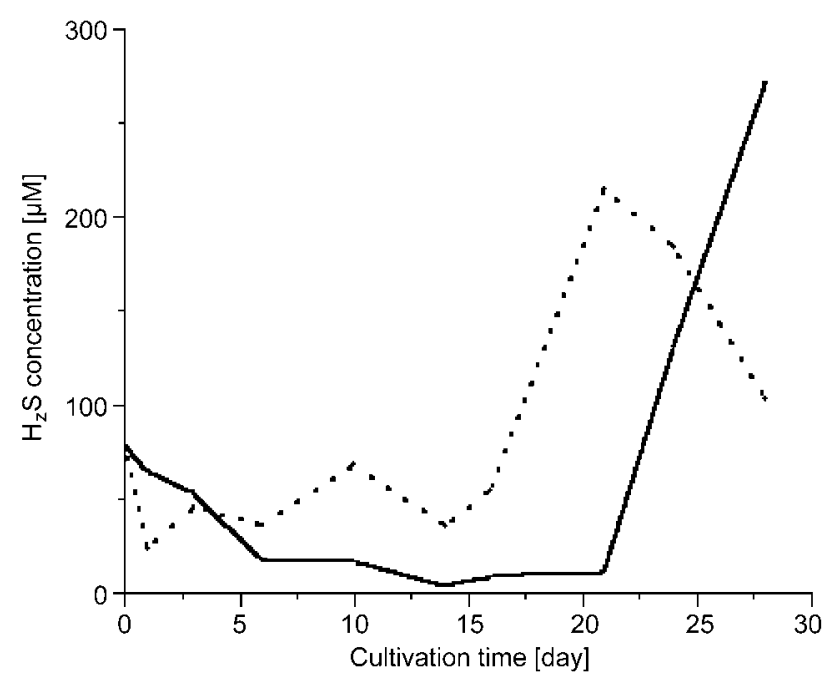

Fig. 6. Hydrogen sulfide level during cultivation of D. acetoxidans with $15.5 \mathrm{mM}$ sulfate (plus $31 \mathrm{mM}$ lactate) (solid line) or $15.5 \mathrm{mM}$ synthetic 3-sulfo-4-hydroxybenzoate (dotted line).

One of the causes could be catalase activity so an attempt was made to prove this by non-denaturing electrophoresis and staining the gel with ferric chloride and potassium ferrocyanide.

The yellow band on the gel $(\sim 25 \mathrm{kDa})$ indicated of catalase activity in phosphate extract from the cell wall of cells from a 10-day culture (Fig. 5).

Additional confirmation of the essential role played by peroxidase in sulfate fixation and transportation into the cytosol was provided by cultures of the studied strain grown in a medium containing synthetic 4-hydroxy-3-sulfo-benzoate or sulfate of the same concentration, besides lactate at the proper molar ratio. Sulfate uptake processes greatly affect both sulfate reduction pathways, but it is easier to ascertain this for the dissimilatory one, by determining its end product-hydrogen sulfide. The results prove that between early third day of cultivation up to the 24 day the $\mathrm{H}_{2} \mathrm{~S}$ level was greater in the culture containing synthetic 4-hydroxy-3-sulfo-benzoate than in the sulfate containing one (Fig. 6).

\section{Discussion}

Until now, bacteria of the genus Desulfotomaculum, like other sulfate-reducing bacteria (SRB), were classified among the so-called strictly anaerobic organisms, However, it is a well-known fact that they can survive exposure to oxygen (Fuseler et al., 1996; Johnson et al., 1997; Eschemann et al., 1999; Brune et al., 2000). Long-term experiments carried out in a laboratory system mimicking proved that oxygen did not exhibit any toxic effect on SRB and did not cause a cessation in their sulfide production (Gutierrez et al., 2008). Taking into consideration that waste- water and oxygen injection was loaded in cycles (up to 16 on a daily), this system acted permanently in the initial stages.

In other SRB, especially the genus Desulfovibrio the antioxidant enzymes: neelaredoxin (Silva et al., 1999), superoxide dismutase (SOD) and catalase (Santos et al., 2000; Brioukhanov and Netrusov, 2004) were found. Also in the examined strain, the presence of neelaredoxin was determined (PawłowskaĆwięk, 2006). Moreover, the strain also revealed antioxidative factors, such as GSH (Pawłowska-Ćwięk and Pado, 2007). However, benzoate and 4-hydroxybenzoate could be found as well (Pawłowska-Ćwięk and Pado, 2005; Pawłowska-Ćwięk, 2006). Nevertheless, the participation of peroxidase is essential to transform benzoate into 4-hydroxy derivative. A supposition on existence of the enzyme suggested that benzoate secretion should have a physiological basis, even regarding the high cost of its biosynthesis $(\sim-200 \mathrm{~kJ} / \mathrm{mol}$ benzoate). An essential reason to secrete the monoaryl might be its antioxidative function, especially at the initial stage of growth, but other factors cannot be excluded.

Gutierrez et al. (2008) showed the detoxification of oxygen injected after $2-4 \mathrm{~h}$ yet and more interestingly, this injection did not cause a cessation in sulfide production by SRB in the biofilm. The present results indicate that most of the oxygen dissolved in media is utilized during the initial period of cultivation, which involves an increase in $\mathrm{H}_{2} \mathrm{O}_{2}$ level (Fig. 1), and is reflected by negative values of the correlation coefficient between oxygen and hydrogen peroxide, also during later period of cultivation (Table I). In SRB, $\mathrm{H}_{2} \mathrm{O}_{2}$ production can result from the neutralization of oxygen anion-radical (e.g. occurring by molecular oxygen) catalyzed by low-molecular $(\sim 14 \mathrm{kDa})$ neelaredoxin and SOD (Silva et al., 1999; Santos et al., 2000; Brioukhanov and Netrusov, 2004). However, SOD and catalase are cytoplasmic or periplasmic proteins while neelaredoxin is an outer membrane protein.

The present results prove that peroxidase occurs in the studied strain, its highest activity falling on days 3 and 13 of cultivation (compare Fig. 1B and Fig. 3). The calculated correlation coefficients indicate that the enzyme activity first of all depends on the concentration of hydrogen peroxide (Table I). It should, however, be pointed out that high values of the coefficient were obtained when the values of $\mathrm{H}_{2} \mathrm{O}_{2}$ from a specific period of the culture were correlated with the values of peroxidase activity from a period shifted one day later. This points to the inductive function of hydrogen peroxide and thus explains high peroxidase activity on the third day of cultivation.

A product of incubation of purified peroxidase, benzoate, hydrogen peroxide and sodium sulfate 


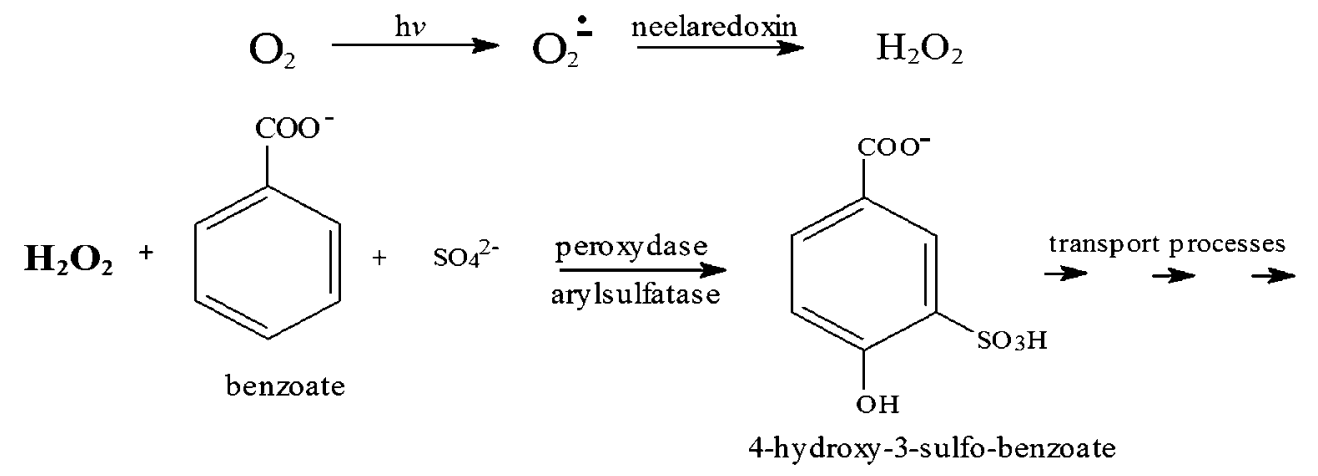

Fig. 7. Proposed sequence reactions in cell wall during initial period of $D$. acetoxidans cultivation.

formed complexes with $\mathrm{Fe}^{3+}$ that displayed absorption maximum at $501.7 \mathrm{~nm}$, which is almost identical with the maximum of an analogous complex formed by synthetic 4-hydroxy-3-sulfo-benzoate (Fig. 4). This is proof that the suggestion of an essential role played by peroxidase is correct, especially in sulfate transport into cytosol as a result of sulfonation of its activity product (Pawłowska-Ćwięk and Pado, 2005). The higher concentration of dissimilated hydrogen sulfide found between days 3 and 24 of cultivation in 4-hydroxy-3-sulfo-benzoate culture than in lactate/ sulfate ones proves that sulfonated 4-hydroxy-benzoate is the proper substrate in the dissimilatory sulfate reduction pathway (Fig. 6). Therefore, the process with the participation of peroxidase is not only an antioxidant defense, but also it affords possibilities of the efficient course of sulfate transport into cytosol in the studied strain (and probably in other SRB). To summarize, the following sequence of reactions in the initial stages of the culture can be suggested (Fig. 7).

Nevertheless, the question rises why peroxidase activity increases on day 13 of cultivation. A certain explanation of the phenomenon might be the occurrence of catalase in the 10 day culture - which produces $\mathrm{O}_{2}$, and that causes an oxygen level increase in the second week of cultivation (compare Fig. 1 and Fig 5). However, this raises another question - where does hydrogen peroxide, the catalase substrate, come from. $\mathrm{H}_{2} \mathrm{O}_{2}$ production by neelaredoxin and SOD is unlikely at low $\mathrm{O}^{-}$, level. Therefore, answering this question needs further research.

\section{Acknowledgements}

I thank Prof. Zdzisław Markiewicz, Tomasz Bator and Wojciech Królik for helpful of the preparation this manuscript.

\section{Literature}

Bartosz G. and M. Bartosz. 1999. Antioxidant activity: what do we measure? Acta Biochem. Pol. 46: 23-29.

Brioukhanov A.L. and A.I. Netrusov. 2004. Catalase and superoxide dismutase: distribution, properties, and physiolo- gical role in cells of strict anaerobes. Biochemistry (Mosc.) 69: 949-962.

Brune A., P. Frenzel and H. Cypionka. 2000. Life at the oxicanoxic interface: microbial activities and adaptation. FEMS Microbiol. Rev. 24: 691-710.

Eschemann A., M. Kuhl and H. Cypionka. 1999. Aerotaxis in Desulfovibrio sp. Environ. Microbiol. 1: 489-494.

Fago J.K. and M. Popowsky. 1949. Spectrophotometric determination of hydrogen sulfide. Methylene blue method. Anal. Chem. 21: 732-734.

Fournier M., C. Aubert, Z. Dermoun, M.C. Duran, D. Moinier and A. Dolla. 2006. Response of the anaerobe Desulfovibrio vulgaris Hildenborough to oxidative conditions: proteome and transcript analysis. Biochimie 88: 85-94.

Francis Jr. R.T. and R.R. Becker. 1984. Specific indication of hemoproteins in polyacrylamide gels using a double-staining process. Anal. Biochem. 136: 509-514.

Fuseler K., D. Krekeler, U. Sydow and H. Cypionka. 1996. A common pathway of sulfide oxidation by sulfate-reducing bacteria. FEMS Microbiol. Lett. 144: 129-134.

Gutierrez O., J. Mohanakrishnan, K.R., Sharma, R.L. Meyer, J. Keller and Z. Yuan. 2008. Evaluation of oxygen injection as a means of controlling sulfide production in a sewer system. $\mathrm{Wa}$ ter Res. 42: 4549-4561.

Johnson M.S., I.B. Zhulin, M.E. Gapuzan and B.L. Taylor. 1997. Oxygen-dependent growth of the obligate anaerobe Desulfovibrio vulgaris Hildenborough. J. Bacteriol. 179: 5598-5601.

Kuever J., J. Kulmer, S. Jannsen, U. Fischer and K.H. Blotevogel. 1993. Isolation and characterization of a new spore-forming sulfate-reducing bacterium growing by complete oxidation of catechol. Arch. Microbiol. 159: 282-288.

Luterek J., L. Gianfreda, M. Wojtaś-Wasilewska, J. Rogalski, M. Jaszek, E. Malarczyk, A. Dawidowicz, M. Finks, G. Ginalska and A. Leonowicz. 1997. Screening of the wood-rotting fungi for laccase production: introduction by ferulic acid, partial purification, and immobilization of laccase from the high laccaseproducing strain, Cerrena unicolor. Acta Microbiol. Polon. 46: 297-311.

McDonnel A. and L.A. Staehelin. 1981. Detection of cytochrome $f$, a $c$-class cytochrome with diaminobenzidine in polyacrylamide gels. Anal. Biochem. 117: 40-44.

Noh S.L., J.M. Choi, Y.J. An, S.S. Park and K.S. Cho. 2003. Anaerobic biodegradation of toluene coupled to sulfate reduction in oil-contaminated soils: optimum environmental conditions for field applocations. J. Environ. Sci. Health Part A Tox. Hazard Subst. Environ. Eng. 38: 1087-1097.

Pado R. and L. Pawłowska-Ćwięk. 2004. Changes during a long-term growth of Desulfotomaculum acetoxidans DSM 771. Acta Biol. Cracov. Series Botanica 46: 101-107. 
Pawłowska-Ćwięk L. 2006. Antioxidant processes in the culture of anaerobic sulfate-reducing bacteria (in Polish). Wydawnictwo Naukowe AP, Cracow, Poland.

Pawłowska-Ćwięk L. and R. Pado. 2005. The role of benzoate secreted by Desulfotomaculum acetoxidans DSM 771 in sulfate uptake. Acta Biochem. Pol. 27: 797-802.

Pawłowska-Ćwięk L. and R. Pado. 2007. Growth and antioxidant activity of Desulfotomaculum acetoxidans DSM 771 cultivated in acetate or lactate containing media. Pol. J. Microbiol. 56: 203-211. Pick E. 1986. Microassays for superoxide and hydrogen peroxide production and nitroblue tetrazolium reduction using an enzyme immunoassay microplate reader. Met. Enzymol. 132: 407-421.

Rabus R. and F. Widdel. 1995. Conversion studies with substrate analogues of toluene in a sulfate-reducing bacterium, strain Tol2. Arch. Microbiol. 164: 448-451.

Santos W.G., I. Pacheco, M.Y. Liu, M. Teixeira, A.V. Xavier and J. LeGall. 2000. Purification and characterization of an iron superoxide dismutase and catalase from the sulfate-reducing bacterium Desulfovibrio gigas. J.Bacteriol. 182: 796-804.

Schink B., A. Brune and S. Schnell. 1992. Anaerobic degradation of aromatic compounds. pp. 219-242. In: Winkelmann G. (ed.) Microbial degradation of natural products, $\mathrm{VCH}$, Weinheim Silva G., S. Olivera, C.M. Gomes, I. Pacheco, M.Y. Liu, A.V. Xavier, M. Texeira, J. LeGall and C. Rodriges-Pousada. 1999. Desulfovibrio gigas neelaredoxin. A novel superoxide dismutase integrated in a putative oxygen sensory operon of an anaerobe. Eur. J. Biochem. 259: 235-243.

Szutowicz A., R.D. Kobes and P.J. Orsulak. 1984. Colorimetric assay for monoamine oxidase in tissues using peroxidase and 2,2'azinodi(3-ethylbenzthiazoline-6-sulfonic acid) as chromogen. Anal. Biochem. 138: 86-94.

Woodbury W., A.K. Spencer and M.A. Stahmann. 1971. An improved procedure using ferricyanide for detecting catalase isoenzymes. Anal. Biochem. 44: 301-305. 